\title{
FUZZY BASED CONTROLLER DESIGN FOR ANTILOCK BRAKING SYSTEM IN MOTORCYCLE
}

\author{
N. VIVEKANANDAN ${ }^{1} \&$ Dr. AJAY M. FULAMBARKAR ${ }^{2}$ \\ ${ }^{l}$ Research Scholar, Department of Mechanical Engineering, D Y Patil Institute of Engineering and Technology \& Assistant \\ Professor, Pimpri Chinchwad College of Engineering, Pune, Maharastra, India \\ ${ }^{2}$ Principal, Department of Mechanical Engineering, Pimpri Chinchwad College of Engineering, Pune, India
}

\begin{abstract}
Automotive safety is of major concern in today's vehicles including Motorcycles. Since 1970's, Anti-lock braking systems (ABS) are introduced in almost every passenger car. ABS are mainly used in four wheelers. But for motorcycles, because of complexity in dynamics and major issues like availability of space, requirements of power, bulkiness it is more challenging. This paper deals with the implementation of Antilock Braking System (ABS) in motorcycle. The various controller-based ABS systems that are commercially used in passenger vehicles, trucks, Buses, etc. are studied for extension in to motorcycle [1][2][3][6]. The aim of this work is to design a Fuzzy based ABS controller for motorcycle in order to obtain required braking performance and to prevent wheel from getting locked in view of dimensions of Motor cycle wheel. The MATLAB/Simulink Environment is used to find the stopping distance and braking torque analytically and a prototype hardware is developed to validate the results experimentally.

KEYWORDS: Motorcycle, Antilock Braking System (ABS), Fuzzy Logic, Stopping Distance, Braking Torque
\end{abstract}

Received: Jun 08, 2020; Accepted: Jun 28, 2020; Published: Sep 26, 2020; Paper Id.: IJMPERDJUN20201444

\section{INTRODUCTION}

In recent years the Anti-lock braking system (ABS) is a significant growth considering the active vehicle safety. The spinning and skidding of vehicle can be avoided by ABS when a vehicle is under emergency braking and thereby it shortens the vehicle's stopping distance. The appropriate rolling of the tire is possible with the hydraulic pressure regulator. But in motorcycles due to the consideration of cost and space limitation, ABS system is not much popular. Hence motorcycle industries and researchers have begun to work on the implementation of ABS in motorcycle. The overall braking performance of a road vehicle is well determined by the stopping distance being an important parameter widely used for evaluating. Vehicle weight, vehicle speed, Stopping Distance, etc. are the main parameters affecting the performance of braking.

The latest survey on motorcycles highlights that motorcycles with capacity more than 250cc without ABS are $37 \%$ more prone to get into fatal motorcycle accidents and it can be brought down by implementing effective ABS in motorcycle [5]. Many control systems exist but out of the different controls logic, Fuzzy logic is the best way to get a solution over this complex model [5][6]. By using, Fuzzy logic that uses the linguistic variables the tedious calculations can be eliminated.

\subsection{Antilock Braking System}

In ABS, electronic and hydraulic Systems are integrated to control the brakes individually and prevents them from 
locking and travel in even slippery roads. When the brakes are applied, the vehicle and wheel speed start reducing, but the reduction in vehicle speed does not always imply the decrease in wheel speed. Under normal slow rotation of wheels, the brakes work normally but under panic braking the brakes are applied so hard that the wheel tends to stop turning and when a skid starts to develop then the ABS comes to operation.

\subsection{Components of $\mathrm{ABS}$}

The major parts of Antilock Braking System of vehicle are wheel speed sensor, Electronic control unit, solenoid valve, Disc brakes, Hydraulic pressure modulator as shown in Figure 1.

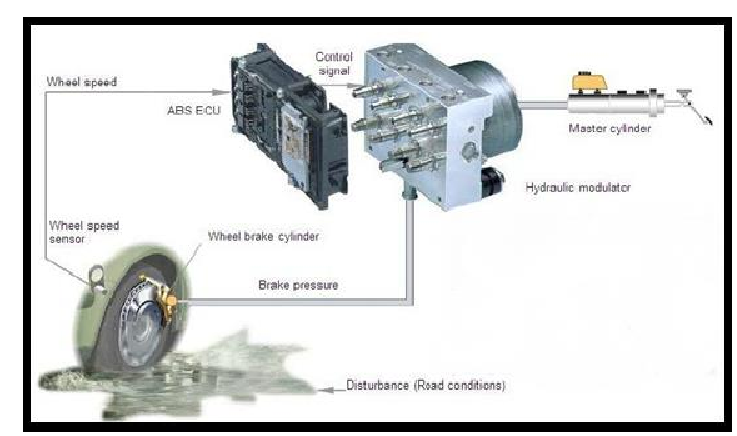

Figure 1: Components of ABS

\subsection{Mu-Slip Ratio for Various Road Surfaces}

The Slip Ratio $(\lambda): \lambda=\frac{\mathrm{V}-\mathrm{R} \omega}{\mathrm{V}}$

As, ' $\lambda$ ' varies from 0 to $1, \mathrm{~V}$ is the velocity of the vehicle and $\mathrm{R}$ is the radius of the wheel and wis the angular speed of the wheel.

- $\quad \mu$ is calculated using: $\mu(\lambda)=\left(\mathrm{C}_{1} *\left(1-\mathrm{e}^{-\left(\mathrm{C}_{2} \lambda\right)}\right)-\mathrm{C}_{3} \lambda\right)$

where, $\boldsymbol{\mu}^{\prime}$ is the Coefficient of friction and $\mathbf{C}_{\mathbf{1}}, \mathbf{C}_{\mathbf{2}}, \mathbf{C}_{\mathbf{3}}$ indicates the constants and constants for different road conditions and their values are shown in Table 1.

Table 1: $C_{1}, C_{2}$ and $C_{3}$ values for Different Road surfaces

\begin{tabular}{|l|c|c|c|}
\hline Surface Condition & $\mathbf{C}_{\mathbf{1}}$ & $\mathbf{C}_{\mathbf{2}}$ & $\mathbf{C}_{\mathbf{3}}$ \\
\hline Dry asphalt & 1.28 & 23.99 & 0.52 \\
\hline Wet asphalt & 0.86 & 33.8 & 0.35 \\
\hline Ice & 0.05 & 306.39 & 0 \\
\hline Concrete & 1.197 & 25.17 & 0.537 \\
\hline
\end{tabular}

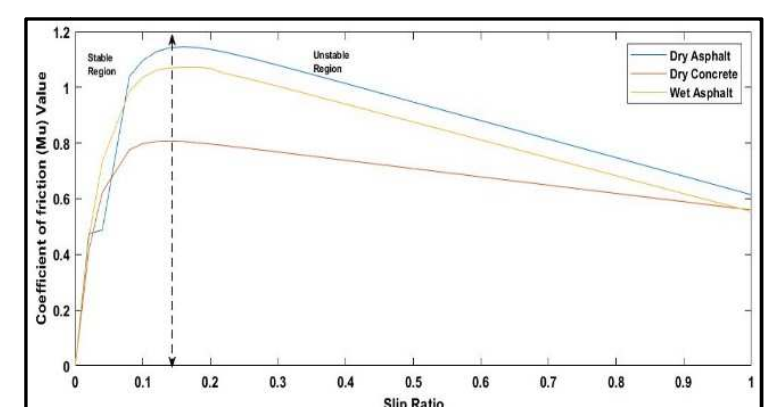

Figure 2: Mu-Slip Curve for Various Road Surfaces 
Regulating the wheel slip at its optimum value to generate larger lateral force with the purpose of maximising longitudinal tyre runway friction is the major purpose of ABS. It is tough to maintain, wheel slip at the peak of $\mu$-slip curve because peak of the $\mu$-slip curve does changes with change in the surface and vehicle velocity. It is observed from Figure 2 that the maximum coefficient of friction is achieved for different road surfaces, when the slip ratio is between $\mathbf{0 . 1 5}$ to $\mathbf{0 . 3}$. Hence, $\mathbf{0 . 2}$ is taken as the reference slip value for designing fuzzy controller.

\section{ANALYTICAL DESIGN USING KINETIC ENERGY APPROACH}

Kinetic Energy of the vehicle K.E. $=\frac{1}{2} m V^{2}$

where, $\mathrm{m}=$ Mass of $($ Vehicle + Rider $)=250 \mathrm{~kg}, \mathrm{~V}=$ Velocity of the vehicle in $\mathrm{m} / \mathrm{s}$

- $\quad$ Tire Friction Force $\left(F_{t}\right): F_{t}=\mu m g$

- $\quad$ Stopping Distance( $S)$ of the vehicle: $\mathrm{F}_{\mathrm{t}} \mathrm{S}=\mathrm{K} . \mathrm{E}$

Hence, $\mathrm{S}=\frac{\text { K.E. }}{\text { Tire-Friction Force }\left(\mathrm{F}_{\mathrm{t}}\right)}$

The table 2 below shows the stopping distance and Tire -Friction Force for different $\mu$ values

Table 2: Stopping Distance \& Tire-Friction Force

\begin{tabular}{|c|c|c|c|}
\hline \multirow{2}{*}{$\boldsymbol{\mu}$ Values } & \multirow{2}{*}{ Tyre-Friction Force, $\mathbf{N}$} & \multicolumn{2}{|c|}{ Stopping distance for different velocities in $\mathbf{~}$} \\
\cline { 3 - 4 } & & $\mathbf{2}$ & $\mathbf{6 0}$ \\
\cline { 3 - 4 } & & 29.4956 & 62.6289 \\
\hline 0.4 & 981 & 23.5964 & 50.1032 \\
\hline 0.5 & 1226.25 & 16.8546 & 35.7880 \\
\hline 0.7 & 1716.75 & $\mathbf{3 0}$ & $\mathbf{6 0}$ \\
\hline
\end{tabular}

\subsection{Brake Force \& Brake Torque Calculations}

$\mathrm{A}_{1}=$ Area of Master Cylinder Piston $=\frac{\Pi}{4} \mathrm{~d}_{1}{ }^{2}=201.0619 \mathrm{~mm}^{2 ;} \mathbf{A}_{2}=$ Area of Calliper Piston $=\frac{\Pi}{4} \mathrm{~d}_{2}{ }^{2}=804.2477 \mathrm{~mm}^{2}$

By Pascal's Law, $P_{\text {master_cyl__piston }}=P_{\text {calliper_piston, }} P=\frac{F}{A}=\frac{F_{1}}{A_{1}}=\frac{F_{2}}{A_{2}}$,

Hence, $F_{2}=F_{1}\left(A_{2} / A_{1}\right)$

As Calliper pressure acts on both the side of disc, The Braking torque $\left(T_{b}\right)$ is given by, $T_{b}=2\left(\mu\right.$ ') $F_{2} r_{\text {disc }}(9)$

Table 3: Brake Torque Calculations

\begin{tabular}{|c|c|c|c|}
\hline $\mathbf{F}_{\mathbf{1}}(\mathbf{N})$ & $\mathbf{F}_{\mathbf{2}}(\mathbf{N})$ & \multicolumn{2}{|c|}{ Braking Torque(Tb) } \\
\hline & & $\boldsymbol{\mu}^{\prime}=\mathbf{0 . 5}$ & $\boldsymbol{\mu}^{\prime}=\mathbf{0 . 6}$ \\
\hline 25 & 200 & 24 & 29 \\
\hline 30 & 240 & 28 & 3 \\
\hline 35 & 280 & 34 & 4 \\
\hline 40 & 320 & 38 & 46 \\
\hline 45 & 360 & 43 & 52 \\
\hline 50 & 400 & 48 & 58 \\
\hline
\end{tabular}

where, $\boldsymbol{\mu}^{\prime}$ is the Coefficient of friction between brake disc and calliper and the braking torque summary is shown in Table 3. 


\section{MATHEMATICAL MODELLING}

As the parameters such as, the lateral motion, vertical motions and the rolling resistance force are not significant in view of braking condition in mathematical modelling and experimental setup, these parameters are neglected.Mathematical model of Antilock Braking System for Bike with and without Controller in the MATLAB Simulink is developed using Newton's Second Law of Motion.[1]

Longitudinal Force $\mathrm{F}=\mathrm{ma}$

Frictional force is given $\mathrm{F}=-\mu \mathrm{F}_{\mathrm{N}}$

Equations of motion are given by, ma $=-\mu \mathrm{F}_{N}$

$\mathrm{J} \omega \alpha=\mu \mathrm{F}_{\mathrm{N}} \mathrm{R}-\mathrm{Tb}$

Hence, state of model can be determined by following equation

$\mathrm{a}=\frac{-\mu \mathrm{F}_{\mathrm{N}}}{m} \alpha=\frac{\mu \mathrm{FNR}-\mathrm{Tb}}{\mathrm{J} \omega}$

\subsection{Two-Wheeler ABS Mathematical Model without Controller}

The ABS mathematical model without the controller is shown in the Figure. 3 in MATLAB SIMULINK environment.

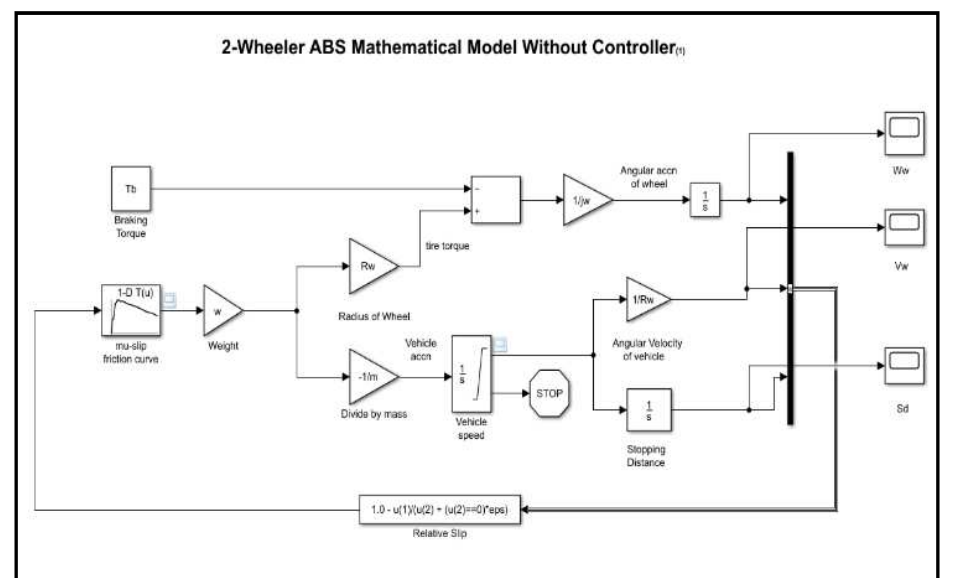

Figure 3: Two-Wheeler ABS Mathematical Model Without Controller

\subsection{Fuzzy Logic Controller Design}

The main operations of a fuzzy logic controller are, a. Fuzzification, b. Inference Engine and c. Defuzzification. They are represented in Figure 4. Mamdani rule base system is used and the rule base requires:

- Determination of appropriate fuzzy sets and the input and output domain range.

- Development of a set of rules for fuzzy inputs and the fuzzy outputs.

- Mapping of crisp inputs to crisp outputs. 


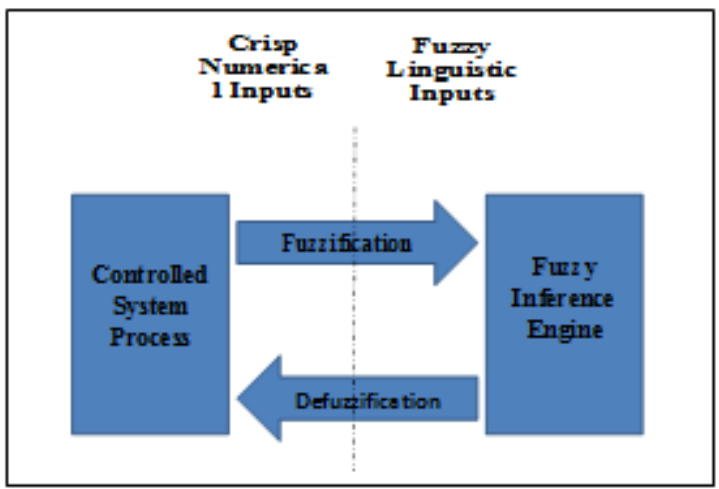

Figure 4: Fuzzy Logic Block Diagram

\subsection{ABS Fuzzy Logic Controller Design}

- Mamdani Fuzzy Logic Controller (FLC) is selected that has two inputs and single output as shown in Figure 5. The two inputs are slip error (E) and rate of change of slip error (CE) and the single output is Brake Torque (Tb).

- There are five membership functions for both.

- Triangular function is selected as the membership function of slip error and rate of change of slip error requires a high sensitivity and the membership function of output braking torque is also high.

- The Language value of input and output parameter - are N - Negative, NS - Negative Small, ZE - Zero, PS Positive Small, P - Positive.

- $\quad$ The developed rule is in the form of, IF (E) IS.....AND (CE) IS....THEN (Tb) IS....as shown in Figure 6.

The following Table 4 represents the Control fuzzy Rules,

Table 4: Fuzzy Rule-Base Table

\begin{tabular}{|c|c|c|c|c|c|}
\hline (CE) & & & & & \\
\hline (E) & $\mathbf{N}$ & NS & $\mathbf{Z E}$ & PS & $\mathbf{P}$ \\
\hline $\mathrm{N}$ & $\mathrm{ZE}$ & ZE & PVS & PVS & PS \\
\hline NS & $\mathrm{ZE}$ & PVS & PVS & $\mathrm{ZE}$ & PS \\
\hline $\mathrm{ZE}$ & PS & PVS & $\mathrm{ZE}$ & PS & PS \\
\hline PS & PS & $\mathrm{ZE}$ & PS & PVS & $\mathrm{P}$ \\
\hline $\mathrm{P}$ & $\mathrm{ZE}$ & $\mathrm{ZE}$ & PVS & PS & PVS \\
\hline
\end{tabular}

\subsection{Description of Fuzzy Rule Base}

When the slip error (E) is $\mathbf{N}$ and the rate of change of slip error $(\mathbf{C E})$ is $\mathbf{N}$ then torque $\left(\mathbf{T}_{\mathbf{b}}\right)$ required is $\mathbf{Z E}$. This indicates that when slip error and rate of change of slip error are not in control then no torque required to be applied in order to achieve required stopping distance. 


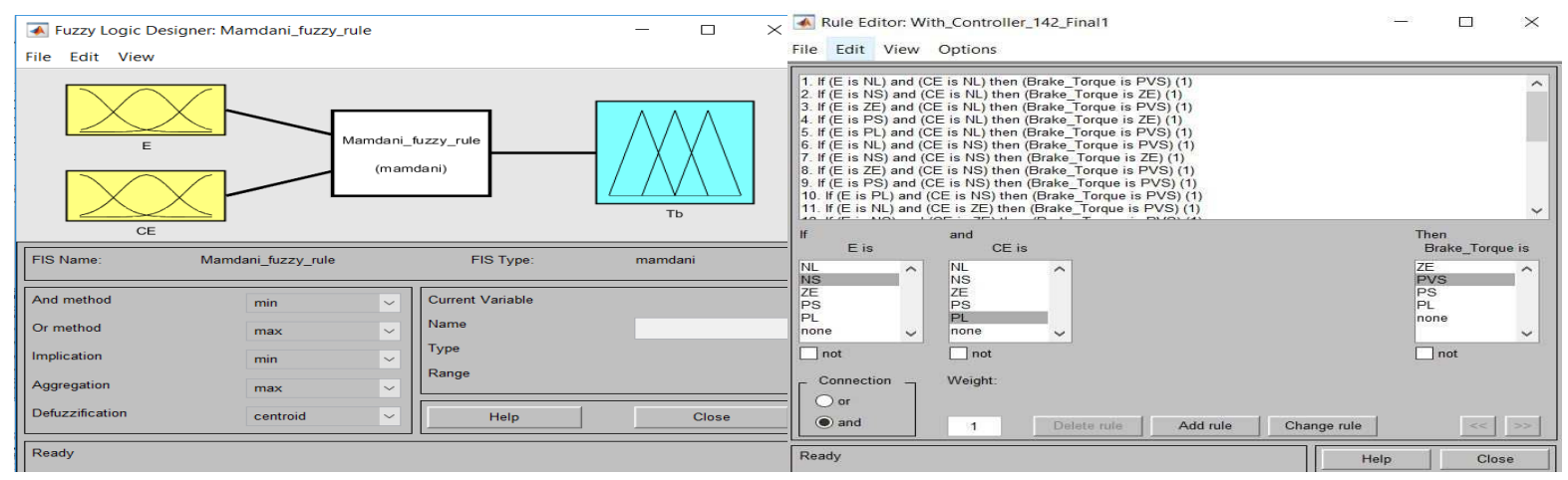

Figure 5: Fuzzy Controller Input and OutputFigure 6: Fuzzy Controller Input and Output

\subsection{2-Wheeler ABS Mathematical Model with Fuzzy Controller}

The 2-Wheeler ABS Mathematical Model with Fuzzy Controller is shown in figure 7 and the Simulation parameter is shown in Table 5.

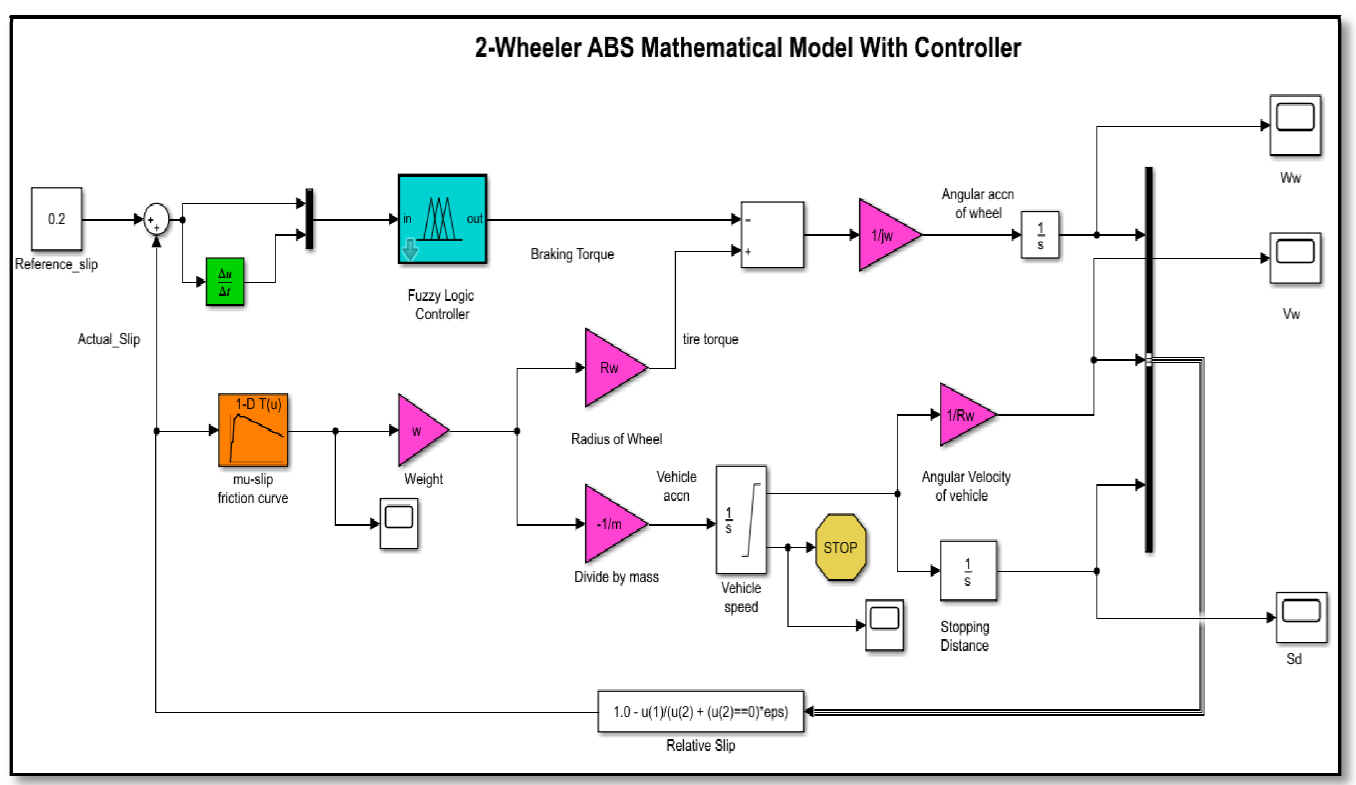

Figure 7: 2-Wheeler ABS Mathematical Model with Fuzzy Controller

\subsection{Simulation Parameter}

Table 5: Simulation Parameters

\begin{tabular}{|c|c|c|c|c|c|}
\hline Parameter & Name & Value & Parameter & Name & Value \\
\hline $\begin{array}{l}\text { Mass } \\
\text { (vehicle + Rider) }\end{array}$ & $\mathbf{M}$ & $250 \mathrm{KG}$ & Dia. of Calliper Piston & $d_{2}$ & $32 \mathrm{~mm}$ \\
\hline Inertia & $\mathbf{J w}$ & $2.2275 \mathrm{Kgm}^{2}$ & Force of Master Cylinder Piston & $\mathbf{F}_{1}$ & Calculated (N) \\
\hline Braking Torque & $\mathbf{T b}$ & $60 \mathrm{Nm}$ & Force of Calliper Piston & $\mathbf{F}_{2}$ & Calculated $(\mathrm{N})$ \\
\hline Weight & $\mathbf{W}$ & $2452.5 \mathrm{~N}$ & Area of Master Cylinder Piston & $\mathbf{A}_{1}$ & Calculated $\left(\mathrm{mm}^{2}\right)$ \\
\hline Wheel Speed & Ww & $\begin{array}{l}31.02 \mathrm{and} \\
62.05 \mathrm{Rad} / \mathrm{sec}\end{array}$ & Ares of Calliper Piston & $\mathbf{A}_{2}$ & Calculated $\left(\mathrm{mm}^{2}\right)$ \\
\hline Parameter & Name & Value & Parameter & Name & Value \\
\hline Vehicle Speed & Vw & 8.33 and $16.66 \mathrm{~m} / \mathrm{s}$ & Radius of wheel & Rw & $0.2686 \mathrm{~mm}$ \\
\hline Gravitational Force & $\mathbf{G}$ & $9.81 \mathrm{~m} / \mathrm{s}^{2}$ & Radius of disc & $\mathbf{r}$ & $0.12 \mathrm{~mm}$ \\
\hline Co-efficient of friction & $\mu$ & 0 to 1 & Slip Ratio & $\lambda$ & 0 to 1 \\
\hline Dia. of Master Cylinder Piston & $d_{1}$ & $16 \mathrm{~mm}$ & & & \\
\hline
\end{tabular}




\section{SIMULATION RESULTS}

The simulation results of the system for standard speeds $30 \mathrm{~km} / \mathrm{h}$ is shown in figure 8 to 12 and for $60 \mathrm{~km} / \mathrm{h}$ in figure 13 17.

\subsection{For 30 KMPH Speed}

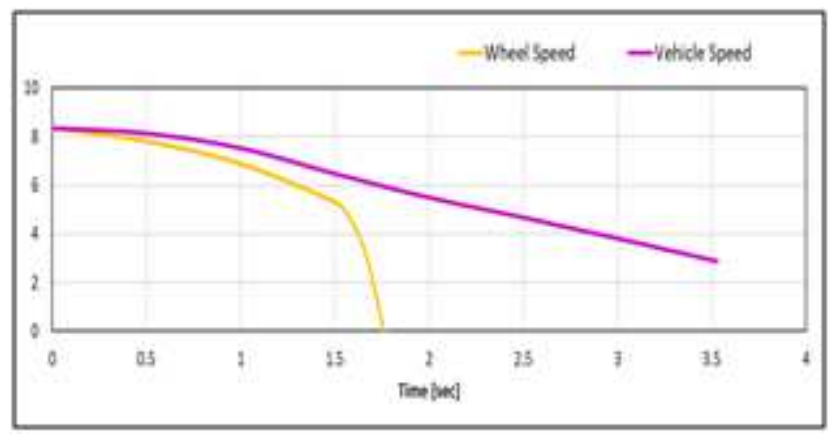

Figure 8: Vehicle Speed Vs Wheel Speed without Controller

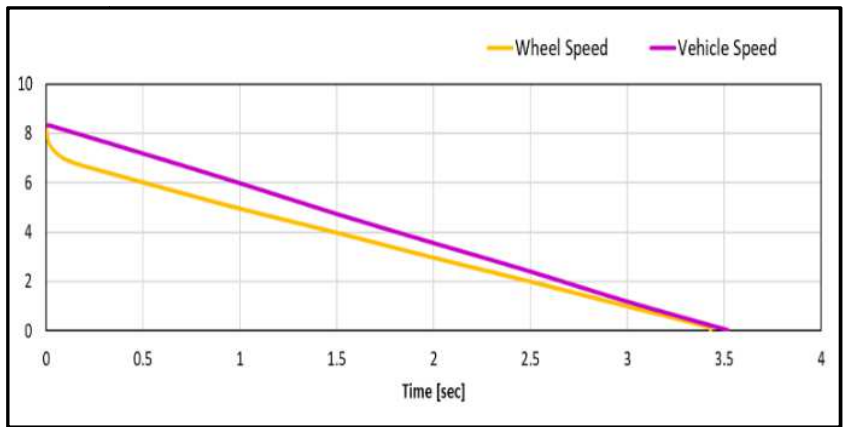

Figure 9: Vehicle Speed Vs Wheel Speed with Controller

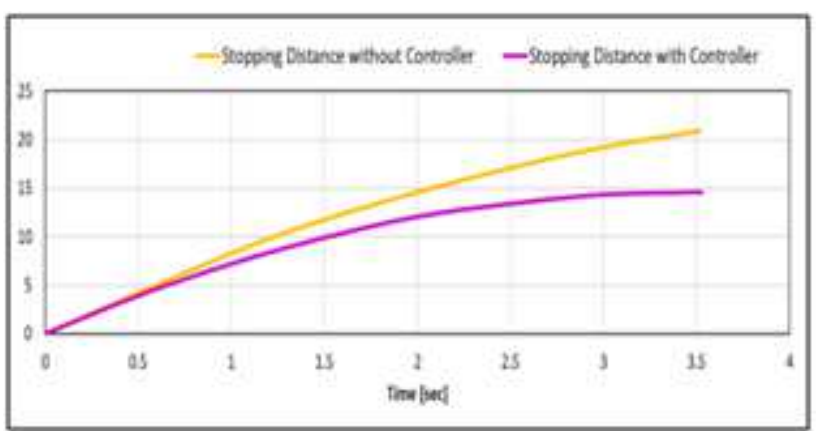

Figure 10: Stopping Distance with and Without Controller

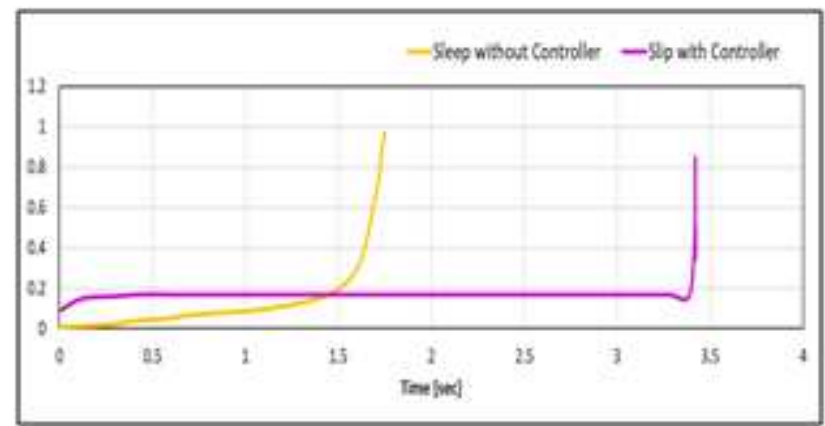

Figure 11: Slip Behavior with and without controller 


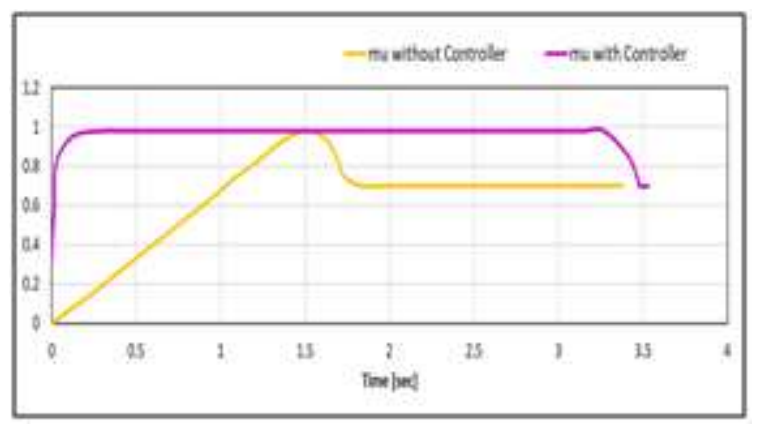

Figure 12: Coefficient of Friction Behavior with and without Controller Model

\subsection{For 60 KMPH Speed}

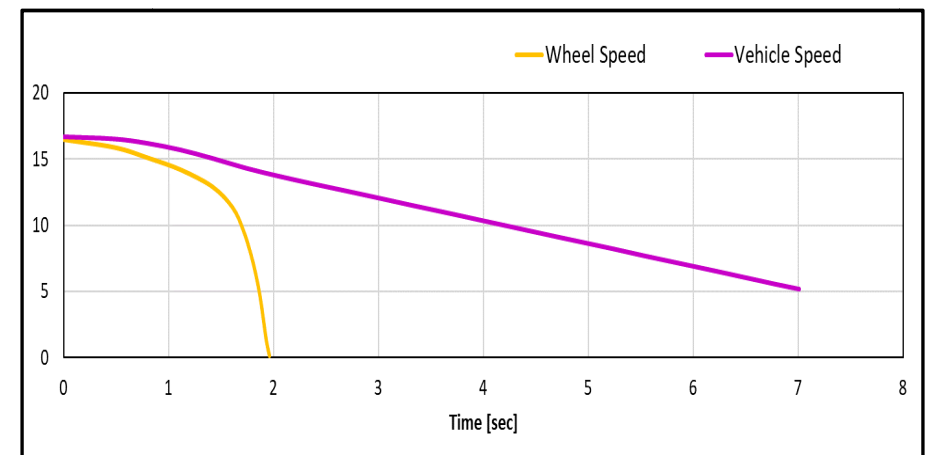

Figure: 13 Vehicle Speed Vs Wheel Speed Without Controller

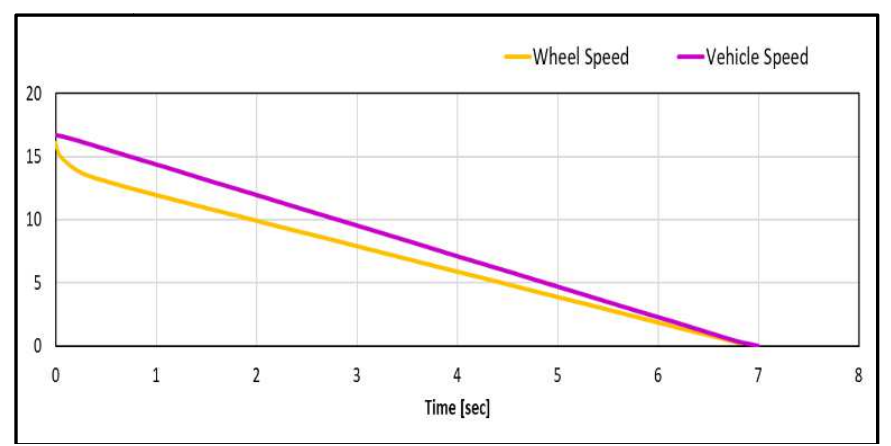

Figure: 14 Vehicle Speed Vs Wheel Speed with Controller

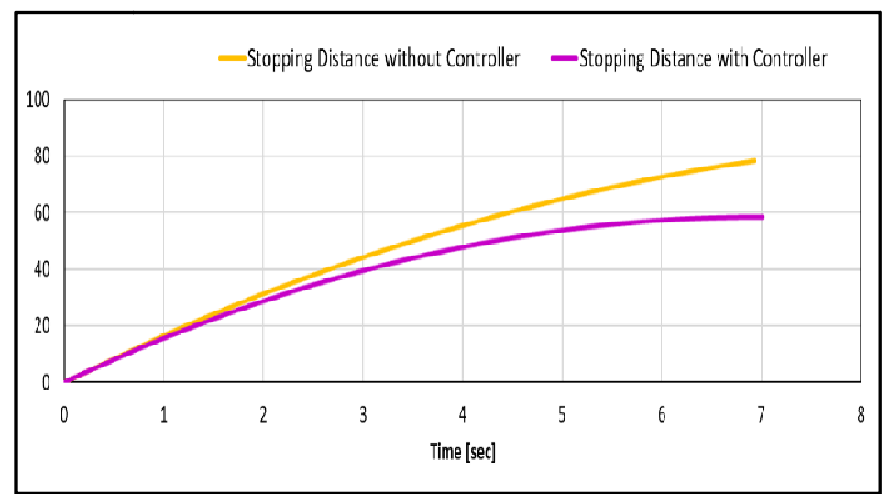

Figure 15: Stopping Distance with and without Controller 


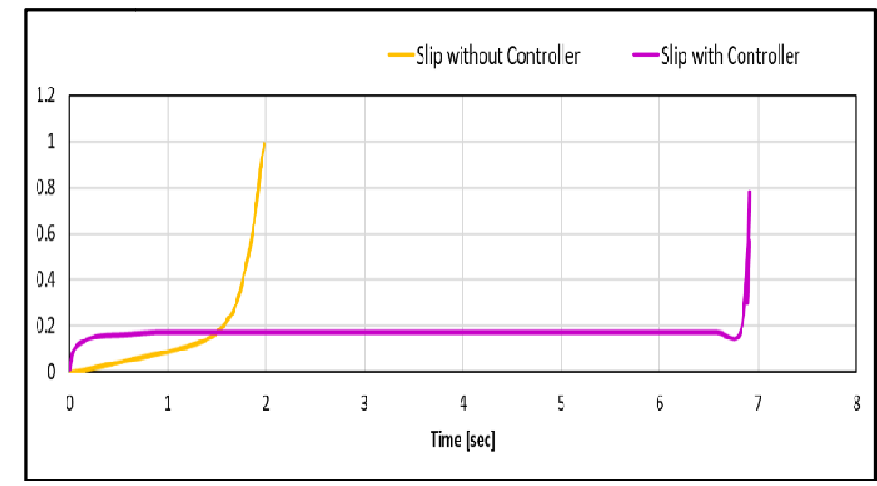

Figure 16: Slip Behavior with and without controller Model

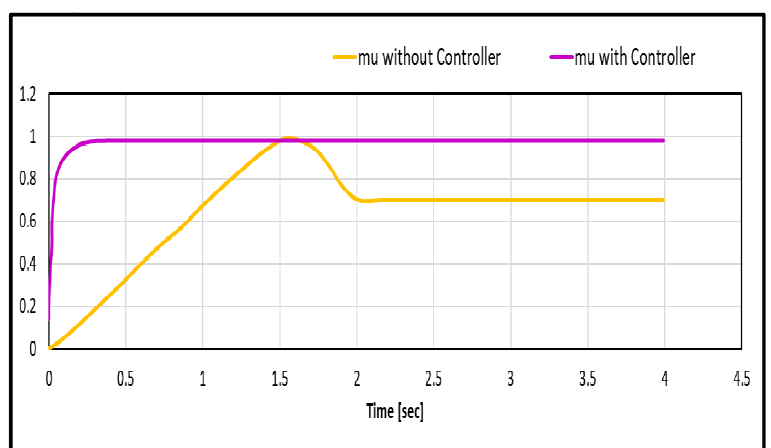

Figure 17: Coefficient of Friction Behavior with and without Controller Model

\subsection{Result Table}

The stopping distance obtained from simulation for the standard speed $30 \mathrm{~km} / \mathrm{h}$ and $60 \mathrm{~km} / \mathrm{h}$ are shown in Table 6

Table 6 Stopping Distance Comparison between with and without controller Model

\begin{tabular}{|c|c|c|c|c|}
\hline \multicolumn{2}{|l|}{ Speed } & \multicolumn{3}{|c|}{ Stopping Distance (m) } \\
\hline KMPH & $\mathbf{m} / \mathbf{s e c}$ & $\begin{array}{c}\text { Without } \\
\text { Controller }\end{array}$ & $\begin{array}{c}\text { With } \\
\text { Controller }\end{array}$ & \% Reduction \\
\hline 30 & 8.3333 & 22.16 & 14.82 & 33.12 \\
\hline 60 & 16.6666 & 76.58 & 58.12 & 24.10 \\
\hline
\end{tabular}

\section{EXPERIMENTATION}

Experimentation is carried on the scale down Prototype model of the system. The scale down Prototype experimental setup is as shown in the Figure 18 below.

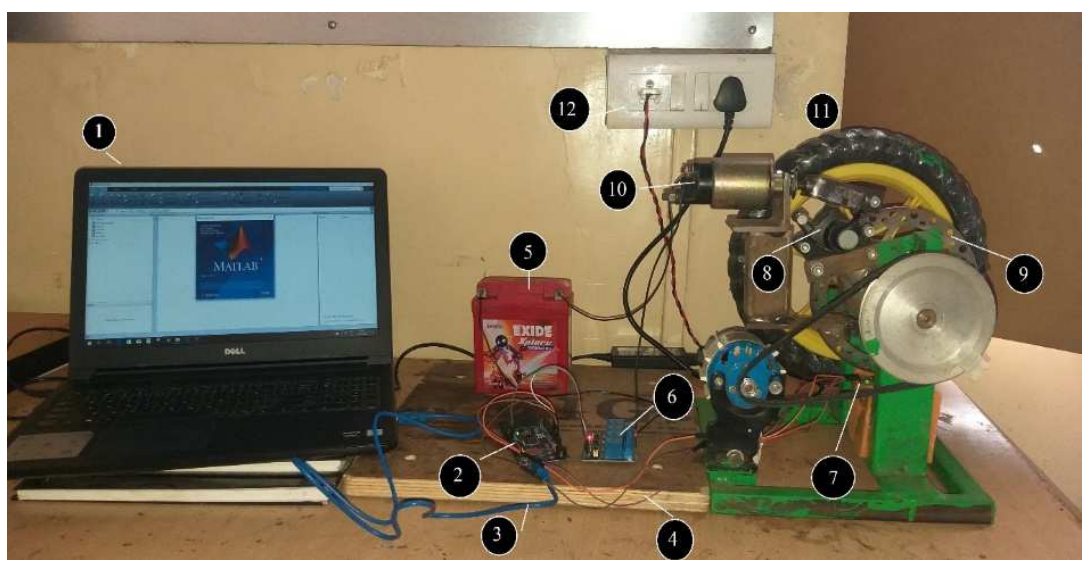

Figure 18: Experimental Setup (Prototype) 
The various components used in the experimental prototype model are mentioned below.

\begin{tabular}{|l|l|l|}
\hline 1. Control System (Laptop) & 5. Battery for Power Supply & 9. Brake Disc \\
\hline 2. Arduino MEGA 2560 & 6. Relay Board & 10. Solenoid Electromagnet \\
\hline 3. Arduino Interface Cable & 7. Speed Sensor & 11. Wheel \\
\hline 4. Connecting Wires & 8. Disc Brake Calliper & 12. Switch \\
\hline
\end{tabular}

Arduino MEGA 2560 Microcontroller is used for interfacing of prototype model. Solenoid Electromagnet is used for obtaining braking effect. Slip based control of braking is not done as less inertia road profile provision does not works effectively. Locking behaviour is observed by varying the actuation of Solenoid Electromagnet with reference to reduction of speed. The number of rotations of wheel are recorded after the direct braking and after the speed-based control braking.

The system does not work when the major component such as the speed sensor becomes contaminated with excess dirt, or when the sensor wires gets damaged that may result in dis-continuity and when actuation of solenoid electromagnet fails. The system may also fail in a corrosive environment.

\subsection{Experimentation Results}

From the experimentation carried out in the experimental setup at standard speed of $30 \mathrm{~km} / \mathrm{h}$ and $60 \mathrm{~km} / \mathrm{h}$, it is observed that number of rotations after direct braking are less compared to the after-speed control braking. This reduction in number of rotations indicates that the wheel locks, in direct braking while it stops after some time with variation rate of actuation of the solenoid electromagnet with respect to speed of wheel and is sensed by speed sensor attached.

Due to less inertia and constraint for the prototype road profile is not given to wheel and fuzzy logic is implemented to avoid the locking of wheel which takes place in real life conditions. Hence speed is measured in terms of RPM through speed sensor and respective signals are given to relay board through Arduino MEGA 2560 microcontroller to operate solenoid valve to stop the wheels not instantly but slowly. This results in reduction of locking of wheel takes place. In experimentation, number of rotations of wheels are measured through speed sensor as shown in Table 7 and figure 19.

Table 7: Number of Rotations After Direct and Fuzzy Based Braking

\begin{tabular}{|c|c|c|}
\hline Trial No & Number of Rotation of wheel after direct Braking & $\begin{array}{c}\text { Number of Rotation of wheel after speed-based } \\
\text { control Braking }\end{array}$ \\
\hline Trial 1 & 3 & 4 \\
\hline Trial 2 & 4 & 5 \\
\hline Trial 3 & 4 & 5 \\
\hline Trial 4 & 3 & 4 \\
\hline Trial 5 & 3 & 5 \\
\hline
\end{tabular}

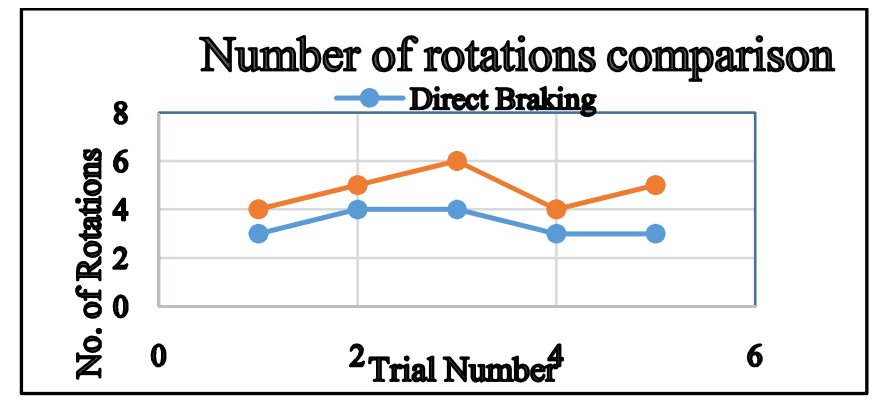

Figure 19: Number of Rotation Comparison

Below Table 8 indicates the comparison of stopping distance obtained from theoretical approach and 
mathematical modelling-based approach.

Table 8: Stopping Distance Comparison

\begin{tabular}{|c|c|c|c|c|c|}
\hline \multirow{3}{*}{ Speed (KMPH) } & \multicolumn{5}{|c|}{ Stopping Distance } \\
\hline & \multicolumn{2}{|c|}{ Mathematical Modelling } & \multicolumn{3}{|c|}{ Kinetic Energy Approach } \\
\hline & Without Controller & With Fuzzy Controller & $\mu=0.3$ & $\mu=0.5$ & $\mu=0.7$ \\
\hline 30 & 22.16 & 14.82 & 39.32 & 23.59 & 16.85 \\
\hline 60 & 76.58 & 58.12 & 83.50 & 50.10 & 35.78 \\
\hline
\end{tabular}

It is observed that the stopping distance obtained for both speed with fuzzy controller model is less than it is obtained from without controller model.as the time taken for both simulation is same because in without controller model wheel locks and skidding takes place while in case of with fuzzy controller model wheel doesn't locks but it stops with reduction of speed in response to varying pressure applied on the brake disc by brake calliper through fuzzy logic controller. As there is $\mathbf{3 3 . 1 2} \%$ Reduction in stopping distance takes place for $\mathbf{3 0} \mathbf{k m p h}$ speed and $\mathbf{2 4 . 1 0} \%$ reduction takes place for 60 KMPH speed.

In the experimentation, scale down prototype model is developed and interfacing of prototype and computer system is done through Arduino MEGA 2560. As due to constraints of components of prototype and less inertia of the physical system road surface for the wheel is not provided so instead of slip and rate of change of slip input parameter for controller is taken as wheel speed which measured in RPM through speed sensor. Then the output voltage is varied based on the fuzzy logic and movement of the solenoid electromagnet is controlled. So, number of rotations after braking are counted using speed controller and it is observed that number of rotations in direct braking case are less in all trials $1,2,3,4,5$ as compare to the number of rotations of wheel in case of fuzzy logic controller-based braking. This indicates that in direct braking wheel locks immediately after continuously application of hard brake while in case of fuzzy controller based braking variation of voltage supply takes place with the reduction of speed which avoids the locking of the wheel due to hard braking.

\section{CONCLUSIONS}

In this work Mathematical Model of Antilock Braking system with and without Fuzzy Controller for motorcycle is created in MATLAB-Simulink software using fundamental equations and principle of Newton's $\mathbf{2}^{\text {nd }}$ law of Motion. It is observed that in general braking stopping distance of motorcycle for various road surfaces is different which is analysed by calculating stopping distance using Kinetic Energy Approach as shown in table 12. For designing fuzzy controller slip parameter is taken as a reference and its value is taken as $\mathbf{0 . 2}$ at which vehicle achieves maximum coefficient of friction on all kind of road surfaces.

After simulation of mathematical model, it is observed that there is significant reduction is stopping distance of motorcycle takes place with the use of fuzzy logic controller in braking system. As controller controls torque applied on the brake disc while braking with respect to varying value of slip and rate of change of slip. Hence, use of fuzzy controller in ABS makes the system more efficient and robust.

In experimentation, scale down prototype is developed and its interfacing with electronic system is done through Arduino MEGA 2560 microcontroller. It is observed that number rotation of wheel after application of direct braking through relay board with actuation of solenoid electromagnet are less as compare to fuzzy based actuation of solenoid electromagnet. Which indicates the wheel in case of direct braking locks after application of continuous brake on disc and 
wheels in case of fuzzy based braking stops by varying the solenoid electromagnet actuation rate with respect to varying speed of wheel which is sensed by speed sensor. So this results in avoiding of locking of wheel while hard braking with the use of fuzzy logic based control system in antilock braking system. The developed fuzzy logic controller reduces the stopping distance of motorcycle along with reduction of the locking of wheels and makes braking system robust for various road surfaces.

\section{REFERENCES}

1. T.K.Berak, Bhattacharya. A.K.Samantaray, "Evaluation of antilock braking system with an integrated model of full vehicle system dynamic", Simulation modelling Practice and Theory 19 (2011) 2131-2150.

2. Harshal Rameshwar More, Aniket AshokraoDigrase, Arjun Vasant Wayse, "Linear Control Technique for Single Wheel ABS (Anti-lock Braking System) of Motorcycle", 2nd International Conference for Convergence in Technology (I2CT), 2017.

3. Chun-Kuei Huang and Ming-Chang Shih, "Design of a hydraulic anti-lock braking system (ABS) for a motorcycle", Springer Journal of Mechanical Science and Technology 24 (5) (2010) 1141 1149,2010.

4. Yogesh Shirke, Jitender, Amit, Akshay Dhingra, "Performance Evaluation of an Anti-lock Braking System", International Journal of Mechanical and Production Engineering”, ISSN: 2320-2092, Oct-2017.

5. Pradeep Rohilla,et.al., "Design and Analysis of Controller for Antilock Braking System in MATLAB /Simulation", International Journal of Engineering Research \& Technology (IJERT), Vol. 5 Issue 04,ISSN: 2278-0181,2016.

6. MissieAguado-Rojas,WilliamPasillas-Lépine, AntonioLoría, "A hybrid controller for ABS based on extended-braking-stiffness estimation", Pages 452-457, Volume 52, Issue 5, ISSN 2405-8963, 2019. 